\title{
Collaboration in the Feminine: Daphne Marlatt / Betsy Warland's 'Re-versed Writing' in Double Negative
}

\author{
Brenda Carr
}

\section{La collaboration au féminin: L'écriture re-versé de Marlatt et Warland dans Double Negative}

Dans une lecture du texte poétique Double Negative, cet essai explore les stratégies de collaboration de Daphne Marlatt et de Betsy Warland dans l'acte d'écrire. Cette collaboration re-verse la tradition littéraire pour faciliter l'emérgence d'une position pour un sujet au féminin, sujet eclaté ce qui déplacera le sujet monolithique et changera des structures sonales oppressives. Le texte confond deux territoires colonisés - le desert australien et le corps de la femme - en risquant l'essentialisme (selon Teresa de Lauretis) pour poser un geste ecoféministe d'une décolonization double. Ce sujet double, deux fois négatif, fini par faire un positif dans cette transformation.

Between our lips, yours and mine, several voices, several ways of speaking resound endlessly, back and forth. One is never separable from the other. You/I: we are always several at once. And how can one dominate the other? Impose hervoice, her tone, her meaning? One cannot be distinguished from the other; which does not mean that they are indistinct.

- Luce Irigaray, 'When Our Lips Speak Together'

As I undertake a reading of the lesbian feminist literary collaboration embodied in Daphne Marlatt and Betsy Warland's Double Negative, I invoke Betsy Warland's vision of the relationship between writers and readers: 'if we write well we invite eavesdropping by the other and with INTEREST: 'interesse, to be in between' s/he hears the difference of an/other's life. it is in difference we understand our lives more profoundly. ${ }^{1}$ Across the difference of sexual orientation, honouring that difference, enspirited by that difference, I listen in on these lesbian lives/lines, and offer my response to Double Negative. 
This textual collaboration enacts a crucial critical intervention: it re-verses literary and socio-cultural grounds to facilitate the emergence of a female-defined collaborative subject position on which female agency, or the ability to change oppressive social practices and structures, may be contingent.

As the informing principle of Double Negative, collaboration not only shapes the concepts, but also the structures of the work. It might be described as a long poem sequence in two parts with a mediating intratextual dialogue between the two writers. Comprised of twelve unsigned lyric poems, the first section, 'Double Negative,' was written during a train trip across the Australian Nullarbor Desert. The dialogue, 'Crossing Loop,' is a transcription of a conversation between Marlatt and Warland (who are in this section identified) reflecting on/theorizing the textual exploration of their desert experience in part one. Taking its name from the Australian term for the side spur where trains wait for other trains to pass, 'Crossing Loop,' is now reframed as a textual waiting place, a place of digression where the text loops back on itself, re-reads itself. Here there is an intratextual collaboration between the creative and the theoretical that extends to an intertextual engagement throughout Double Negative with theoretical concerns outside the work. In the third section of Double Negative, the title, 'Reel 2 ' puns on the notion of a movie reel and of a woman's 'real' multiply defined in this collaborative venture. 'Reel 2 ' literally double crosses the textual terrain, enacts a double take by the double subjects of the writing, opening up the horizons of possibility for female textual and cultural agency. This section is composed of twelve unsigned prose poems each of which takes a phrase quoted from the corresponding poem in the lyric sequence as its improvisational base. Daphne Marlatt recalls the act of composition as being one of handing the notebook back and forth, a collaborative alternation in which the two women each wrote half the poems in the various sections. The resulting dense textual weave calls to mind a cat's cradle as intratextual resonances criss-cross between and within the lyric section, the prose poem section, and the 'Crossing Loop' dialogue. In their co-written essay 'Reading and Writing Between the Lines,' Marlatt and Warland address this intratextual doubling: 'not simply a working together there are challenges backings up required words we graft from each other's texts that can't be later edited out.' ${ }^{2}$

While Wayne Koestenbaum's Double Talk discusses the way the 
doubling of voices between such men as T.S. Eliot and Ezra Pound both signals and camouflages their homoerotic connection, recent lesbian collaborations, both creative and critical, in no way function as double talk. ${ }^{3}$ Rather, such works as Suniti Namjoshi and Gillian Hanscombe's Flesh and Paper (1986) and Gillian Hanscombe and Virginia Smyers's Writing for Their Lives: The Modernist Women (1910-1940) manifest what Nicole Brossard calls 'rapproche-ment, the result of a collective practice of semantic divergence' from intersecting gender and sexual ideologies. ${ }^{4}$ As a revisionist history of literary modernism, Writing for Their Lives, in its focus on such lesbian couples as Alice B. Toklas and Gertrude Stein, Virginia Woolf and Vita Sackville West, H.D. and Bryher, and Amy Lowell and Ada Russell, celebrates the way that the doubling of lesbian tongues frequently facilitates female cultural agency. Loving collaboration between these modernist women often took the pragmatic form of financial support, and aesthetic encouragement, with a resulting increase in representations of lesbian subjectivity.

There is a similar blurring of female erotic and textual activity in Double Negative, where Marlatt and Warland's double signature on the cover is the first indication of their lesbian collaboration. However, their refusal to sign poems within the body of the text calls into question the very notion of ownership of texts, and implies that they do not wish to claim textual or sexual authority over each other. Marlatt and Warland speak to this issue in 'Reading and Writing Between the Lines':

here we acknowledge that all writing is collaboration here we question the delineation between the collectivity and the individual's ownership of the written here we affirm our spiralling dominoing wandering she-speech in the talking we do between the sheets between the lines between the writing that intertwines ... ${ }^{5}$

In this passage, slippage occurs between the scenes of womanto-woman reading, writing, talking, and making love, as is the case in Double Negative. Further, Marlatt and Warland reconfigure the binary privileging of the written over the spoken by oralizing the poem, each quoting phrases from the other's voice in conversation. As well, six of the prose poems end with a similar question - 'what is woman' (on a train, in the desert, in her own fiction, in her emptiness, 
in her own symbolic, in her ecstasy) - questions which call the reader to collaborate with the textual desire for the birth of the female subject. Such ambiguities of writing subject and of text, of the spoken and the written, and of the writer and the reader, are fundamentally a means of de-authorizing the female autorgraph, of rejecting the mantle of mastering discourse.

\section{ii.}

rock bottom sea bed we lie in you pulled me under last night sucking me out through my womb inside out re-versed writing across bed into sky touching holding everything words my only boundary the desert on either side of my mind ${ }^{6}$

Two lesbian bodies writing in reverse, reversing the direction of writing. 'Re-versed,' on one level, reflects Marlatt and Warland's literal experience of writing while sitting in train seats facing backwards. Movement in reverse is double as they engage in 're-vision' of literary ground, in Adrienne Rich's sense of 'entering an old text from a new critical direction. ${ }^{7}$ Such re-versing facilitates transformation of the historical subject of poetry from monolithic, male, and heterosexual to multiple, female, and lesbian. Old texts that are re-versed include two of the mastertexts of Western literature - the love lyric and the long poem. Intersecting with these literary texts are the cultural texts, those gender and sexual ideologies that prescribe the norms of 'femininity' and 'compulsory heterosexuality.' ${ }^{8}$

The love lyric has historical connections with the Petrarchan sonnet which conventionally involved a male speaking subject and a mute female body - fantasized, fragmented, and fetishized - as the object of his discourse. ${ }^{9}$ Double Negative re-verses the historically male-defined and heterosexual economy of the love lyric with its two female subjects, two beloveds speaking each to each. In a parallel manner to the love lyric, the long poem is invested with ideological and genre concerns that are affiliated with those traits culturally designated as 'masculine.' It is associated with the epic, which may be seen as a warrior or explorer narrative. The 'Crossing Loop' dialogue indicates that the literary tradition Marlatt and Warland explicitly see 
themselves re-versing is a member of the family of explorer narratives - the travel account of a journey by train. Writing Double Negative is for Marlatt an act of 'rewriting the train experience from a female perspective' (38).

One way Marlatt and Warland shift the referential ground is to re-verse the masculine coding of words associated with the train in the male explorer narrative tradition. The speaker of 'imagin-a-nation in the heart of' puns with the notion of a linear train of thought that stays on track like linear sentence and narrative construction to de-rail the male explorer tradition: 'imagination a-muses herself with the emptiness of words and boards the train of the sentence empty handed and makes off with it deriding the end point of the Final Product ... she is well on her way to de-railing the 'long straight' which can only see its own track' (50). In 'Crossing Loop,' Betsy Warland theorizes the countermotion of her literal experience of the crossing loop as an alternative to the one track 'long straight': 'the train is constantly starting and stopping, departing and arriving, coming and waiting at crossing loops and in that sense it's cyclical' (37).

'Shifting referentiality's locus,' as Warland describes the textual gesture in 'Crossing Loop,' not only involves re-configuring the literary genres and their attendant conventions, but also re-versing direction to take a stance counter to the dominant culture (38). Most explorer literature unquestioningly celebrates that uncontested right institutionalized by church and state, the right of the explorer to claim dominion over the land he journeys through. Marlatt and Warland directly engage the historical trace of colonization in the Australian desert by questioning the Anglicized place names: 'signs mutating like mixed metaphors/Peterborough, Jamestown, Gladstone, Port Pirie/ anglo overlays in the name of/see-vill(ain)-I-say-tion' (19). The phonetic word play suggests the way that a civilization based on the mastering gaze and the authoritative word both originate from the capital I/ eye, and can be seen as an act of villainy against original (in this case aboriginal) peoples. This displacement of ' $a b /$ original' names is symptomatic of the displacement of an entire language, an entire way of life, which Marlatt and Warland consciously desire to honour, while acknowledging their cultural difference from it:

'from the beginning'

$\mathrm{ab} /$ original 
we use their words for things, places

and they are different in our mouths

the oldest living language group in the world

we don't know where they came from

we can't go back

not to the roots we know

Indo-european words, dead wood

sentences tracking

across the untracked, the

intractably here (14)

Marlatt and Warland assert their desire to 'lose the proper train of thought,' get 'off the track,' and to 'untrain' themselves to 'undermine every prop(er) deafinition,' those terms learned from their schooling in a dominantly white culture (51). Their text enacts linguistic decolonization by bringing in aboriginal place names: 'Yunta, Paratoo, Ucolta, Yongala ...'the oldest living language' shaping our tongues lips/to speak it out (though we do not know the meanings)/magnetic field of sounds/mouths move in anOther motion' (16).

Honouring other cultures as a gesture of decolonization is one manifestation of Marlatt and Warland's ecofeminist position that connects the colonization of women and minority groups with that of the earth and its creatures. (And here note that I use colonization in its broader metaphoric sense of territorialization rather than in its historic sense.) Linking the word that names territories with the gaze that lays claim to them, Marlatt and Warland contest the centrality of the gaze to explorer narratives and Western culture. Their focus on the gaze as a signal of cultural authority borrows from recent film theory's exploration of the way that a figure in a given frame whose gaze is dominant usually has control of the narrative action. In '10:33/ Forrest,' the speaker notes:

far as the eye can see

there are birds, insects, mammals, reptiles, scrub trees, bushes, grasses

thriving outside The Gaze

(can we see what we do not value) (24) 


\section{Collaboration in the Feminine $\cdot 117$}

Here re-versed writing involves shifting the ground of 'The Gaze,' shifting the Western European and androcentric point of view to retrain the mind to value other cultures and other life forms usually viewed as valueless or 'negative.'

Marlatt and Warland's Double Negative situates itself at the intersection of the possible meanings for the word 'negative,' making the term vitually reversible. I want to meditate here on some of these meanings. Negative resonates with cultural prohibition in '17:00/ coming into Port Pirie':

walking into the diner

'are you ladies alone'

'no'

'we're together'

i look out the window

deja vu:

nothing looking at nothing

two women outback

down under

add it up - two negatives make a positive (20)

Two women lovers already inscribed (deja vu) by the male Gaze as nothing looking at nothing. As they do here, negative terms manifest denial-'nothing'/'not'/'no'. What the Gaze does not recognize does not exist. However, Marlatt and Warland's double text re-verses the gaze to bring the double cultural negatives 'lesbian' and 'woman' out into the textual open, to make visible what the Gaze declares invisible. Playing with the sense of a photographic negative or 'reverse impression' in which lights and shadows are reversed and from which positive prints are made, they reframe the cliche 'two negatives make a positive' to shift the terms of their own lesbian existence. In multimedia collaboration with the concept of positive negatives, the negative collages by Cheryl Sourkes on the front cover of Double Negative and intercut within the text as section dividers provide a visual equivalent for the textual reversal. The sense of a dissenting negative that 'refuses consent' also comes into play as the speaker in '17:00/ coming into Port Pirie' asserts: 'women as CONS: contra, against, opposite' to Pros.' Pros are undoubtedly the descendants of the Explorers for they continue to claim aboriginal lands in the Australian outback, mine their sacred sites for uranium, a charge laid elsewhere in a prose 
poem, and declare such places as Woomera a 'prohibited area ... weapons testing range' (19).

At the end of 'coming into Port Pirie,' the text uses graphics in a manner resonant with Concrete Poetry and Lettrism to conflate the grounds that have been prohibited and to re-verse the terms in an ecofeminist gesture of double decolonization:

off the map

opening up the Subject

hands a manual alphabet

CONS: 'French, cunt'

i sign your $\mathrm{V}$

PROHIBITED AREA

the imaginary

two women in a birth (21)

The 'PROHIBITED AREA' is now marked specifically as the female sex, seemingly declared of limits to the female lover, seemingly declared to be always already 'occupied' like the aboriginal lands. But there is subversive action as the lover initiates a new manual alphabet, tracing/writing the sign of the $V$, explicitly coded in another passage as the graphic equivalent of the venus mound, on the body/text of her beloved. This is a symbolic gesture suggestive of cultural authority (I sign you with the sign of the V). The V shifts the gaze from the phallus as a term of reference in the Lacanian theory of subject formation to the Venus mound. Defined by lack because it is minus phallus, this symbolic (non) marker of a female subject position is symbolically re-versed as a resonant passage from one of the prose poems reveals: 'writing the not here inverts turning perspective upside down' (54). The text performs a lettrist meditation on the shape of the $V$, lovingly inhabits and explores the 'negative feminine space' to invert point of view. This is the V-space which Marlatt and Warland's re-versed writing spirals around: 'Your Mound of V pulling me/ o contraction Star of V-us/first letter of another alphabet/lit language we star(e) at/we will open the bed and chant our stars down/into the sway of unuttered texts ... as the matter of language reinvents itself all over again' (28). The V of the venus mound, the, is the matter, the material of an alternative alphabet, the centre of a constellation of possible texts. 
The $\mathrm{V}$ used as lettrist sign for the female sex first appears in a fantasy at the end of '14:50 Peterborough.' Here the desert geography of 'soft mound of hill lost/dip or cleft' is conflated with and fantasized as the geography of the female body. While such conflation may seem to reproduce a representation typical of explorer literature in which the land is imaged as virgin, as ripe and ready for entry, it directly re-verses the terms. The text declares this female fantasized ground to be the realm of the 'imaginary,' which Marlatt and Warland use in Nicole Brossard's sense to mean that territory 'constituted by female subjectivity (and) traversed by a feminist consciousness. ${ }^{10}$ The fantasizing of the landscape as the $\mathrm{V}$ of the Venus mound is a collaborative act of literary intervention. It facilitates entry into a femaledefined imaginary that the collective 'we' enters. Here, as the end of 'coming into Port Pirie' also suggests, the monolithic Subject is opened up to allow for the birth of a twinned subject: two women in a train berth giving birth to each other as desired and desiring subject in and for each other's writing.

From Marlatt and Warland's ecofeminist point of view, the Australian desert is the literal and metaphoric geographical equivalent to the 'negative feminine space' of lesbian doubling, as the writer of a prose poem in 'Reel 2' suggests: 'the desert a different economy (her own woman?) ... (land) not worth developing where women's desire $X$ changes into a foreign current/cy ('Men can't get a living from')' (46). The language of this passage resonates with Luce Irigaray's vision of a feminocentric sexual 'economy of abundance' where women refuse to go to market, choosing rather to maintain 'another' kind of commerce, among themselves.' 11 Re-versing the conventional vision of the desert as negative space, a transformation is enacted from 'the desert site of His testing' to 'the desert site of Her texting' - a counter inscription of the currents of woman-to-woman desire within the desert expanse of shifting boundaries (49).

The potentiality of the desert as a no man's land, a limitless margin, a boundless text, is explored in the prose poem 'two women in a birth':

what if the boundary goes walking? refuses to be that place the hero enters with his gold his drums his caravans ... bleak obstacleboundary-space to and for his adventures ground to his figure and exploits ... she has rolled over in all that red dust ... given herself a shake and birthed into subject. the inconceivable 
doubling herself into life no slouch-backed beast (even double humped) heading for Bethlehem but the doubling of 'woman' into hundreds camped in the middle of desert outside Pine Gap's nuclear base, and the voice of the desert is the sound of their singing out their anger relentless and slow as dunes walking. we are off the train in order to be in the desert no long the object of exchange but she-and-she-who-is-singing (as the women have always sung) this body my (d)welling place, unearthed.

The desert as the scene of male exploration and exploitation in the cultural and literary contexts is now a twinned site of ecofeminist resistance. Writing against the circumscription of women's reproductive capacity within a male sexual economy, the terms of giving birth are re-versed. The desert becomes the place of 'inconceivable doubling' or lesbian parthenogenesis. Using Yeats's 'Second Coming' as a re-visionist countertext, the writer of this passage exposes the way such feminocentric reproduction minus male, minus phallus is construed as monstrous, in violation of dominant cultural prohibition, and subverts this version. No monster here slouching toward singular birth; no 'double-humped beast' of heterosexual coupling either.

At the scene of lesbian doubling, female subjects proliferate. The desert personified as 'she' - waking up after years of playing the 'obstacle-boundary-space' to the desert fathers - is also the female subject in and for this writing. This conflation of female subject position with geographical space resonates with the earlier fantasy of the desert landscape as the mound of venus. Such a textual connection between two colonized territories - desert and female body becomes the means for a literal and symbolic gesture, an ecofeminist gesture of double decolonization. In an interview that I recently conducted with Daphne Marlatt, she indicates that geographically based imagery used as an embodiment of woman-to-woman eroticism may be seen as a self-conscious recuperation of the androcentric reduction of woman to nature, a space outside of cultural production and social agency. ${ }^{12}$

Marlatt and Warland's eco-feminist position takes what Teresa de Lauretis calls 'the risk of essentialism.' This involves seeing' an essential,' 'irreducible' difference vested in 'a feminist conception of woman, women, and the world,' rather than belief in an essential 
male/female difference inherent in 'woman's nature.' As a conceptual category defined by 'a totality of qualities, properties, and attributes that ... feminists define, envisage, or enact for themselves ... and possibly also wish for other women,' this type of essentialism is 'more a project ... than a description of existent reality.' ${ }^{13}$ In Linda Hutcheon's terms this project is the manifestation of feminisms' belief in a meta-narrative of feminist commitment to transform, not merely contest, as postmodernism does, the interlocking systems of domination. ${ }^{14}$ Critiquing a feminist conceptual essentialism as a reproduction of entrapping patriarchal essentialism is fundamentally reductive. In Marlatt's words, it ignores 'the large contextual shift' that the ecofeminist position facilitates: 'to say that this leaves women outside of culture is to speak from patriarchal ground, because it suggests that there is only one recognizable culture, the dominant patriarchal one, and it denies the radically new culture being born out of that contextual shift. It's hard to recognize this culture because it isn't monolithic or singular. It's more like an area of response between different oppressed or minority cultures. ${ }^{15}$

As a fantasized image for a meta-narrative of ecofeminist transformation, the multiple female subject who is birthed in the desert and as the desert in 'two women in a birth' is significant. The voice of the desert and the sound of the women singing protest songs at the nuclear base merge with the women writers' voices - a collective reclaiming of territorialized space. Lesbian collaboration in Double Negative suggests a symbiotic relationship among female collaboration, cultural agency, and subject formation. If the days of the Lone Ranger are over, it seems that women cannot enter the realm of the symbolic, the realm of cultural and social agency, in solo. Lesbian doubling in the desert/text, giving birth each to the other, opens the horizons of possibility for heterosexual women as well. It is in the collaborative action where the cultural negatives (woman, lesbian, desert) are re-versed, in the solidarity of 'she-and-she-who-is-singing,' that I find myself as a woman written into the lesbian text. As Marlatt and Warland suggest in 'Writing and Reading Between the Lines,' the principle informing their texts is extended to the reader: 'eroticizing collaboration we've moved from treason into trust. a difficult season, my co-labial writer writing me in we while we are three and you is reading away with us. ${ }^{16}$ Such a co-labialization between women written and reading calls into being inside out, re-versed 
writing, which performs crucial critical intervention across our differences at the intersection of literary and social practices.

\section{Notes}

I am grateful to Sue Schenk for her invaluable editorial comments, and to Daphne Marlatt and Betsy Warland for their openness to collaboration with their readers.

1. Betsy Warland, 'as a writer, what is my relationship to LITERATURE,' SP/ELLES (Windsor: Black Moss, 1986), 112.

2. Daphne Marlatt and Betsy Warland, 'Reading and Writing Between the Lines,' Tessera 5 (1988), 85.

3. Wayne Koestenbaum, Double Talk: The Erotics of Male Literary Collaboration (New York: Routledge, 1989).

4. Nicole Brossard, The Aerial Letter, trans. Marlene Wildeman (Toronto: The Women's Press, 1988), 105-106.

5. 'Reading and Writing Between the Lines,' 87.

6. Daphne Marlatt and Betsy Warland, Double Negative (Charlottetown, Prince Edward Island: gynergy books, 1988), 25. Subsequent references to the text will be cited by page within the paper.

7. Adrienne Rich, 'When We Dead Awaken,' On Lies, Secrets, and Silence (New York: Norton, 1979), 35.

8. Adrienne Rich, 'Compulsory Heterosexuality and Lesbian Existence,' Blood, Bread, and Poetry (New York: Norton, 1986).

9. See Nancy J. Vickers, 'Diana Described: Scattered Women and Scattered Rhyme,' Writing and Sexual Difference, ed. Elizabeth Abel (Chicago: UP of Chicago, 1982), for discussion of the fragmentation of the female body in the Petrarchan sonnet.

10. 'From Radical to Integral,' Aerial Letter, 113.

11. Luce Irigaray, 'Commodities Among Themselves,' This Sex Which Is Not One, trans. Catherine Porter (Ithaca, New York: Cornell UP, 1985), 196.

12. Brenda Carr, 'Between Continuity and Difference: an Interview with Daphne Marlatt,' forthcoming in TishNOW, ed. Douglas Barbour.

13. Teresa de Lauretis, "The Essence of the Triangle or, Taking the Risk of Essentialism Seriously: Feminist Theory in Italy, the U.S., and Britain,' difference 1 (Summer 1989), 5.

14. Linda Hutcheon, 'Incredulity Toward Metanarrative: Negotiating Postmodernism and Feminisms,' Tessera 7 (1989), 41.

15. 'Between Continuity and Difference.'

16. 'Reading and Writing Between the Lines,' 88. 